\title{
Switching from reference infliximab to CT-P13 in patients with inflammatory bowel disease: 12 months results
}

\author{
Federico Argüelles-Arias ${ }^{a}$, Maria Fernanda Guerra Veloz ${ }^{a}$, Raul Perea Amarillo ${ }^{a}$, Angel Vilches-Arenas ${ }^{b}$, \\ Luisa Castro Laria ${ }^{a}$, Belen Maldonado Péreza ${ }^{a}$, Dina Chaaro Benallal ${ }^{a}$, Antonio Benítez Roldán ${ }^{a}$, Vicente Merino ${ }^{c}$, \\ Gabriel Ramirezc, Miguel Angel Calleja-Hernández ${ }^{c}$ Angel Caunedo Álvarez and Manuel Romero Gómez ${ }^{\mathrm{a}}$
}

Background Biological agents, such as infliximab, have transformed the outcomes of patients with immune-mediated inflammatory diseases. The advent of biosimilar treatment options such as CT-P13 promises to improve the availability of biological therapy, yet real-world switching data are currently limited. Here, we assess the effectiveness and safety of switching to CT-P13 from infliximab reference product (RP) in patients with inflammatory bowel disease.

Materials and methods This was a prospective single-center observational study in patients with moderate to severe Crohn's disease (CD) and ulcerative colitis (UC). All patients were switched from infliximab RP (Remicade) to CT-P13 treatment and followed up for up to 12 months. The efficacy endpoint was the change in clinical response assessed at 3-monthly intervals, according to the Harvey-Bradshaw score and partial Mayo score for patients with CD and UC, respectively. C-reactive protein (CRP) was also measured. Adverse events were monitored and recorded throughout the study.

Results A total of 98 patients with inflammatory bowel disease (67 CD/31 UC) were included. A total of 83.6\% (56/67) of patients with CD were in remission at the time of the switch and $62.7 \%$ were in remission at 12 months. The Harvey-Bradshaw score showed a significant change at 12 months $(P=0.007)$ but no significant change was observed in median CRP at this timepoint $(P=0.364)$. A total of $80.6 \%(25 / 31)$ of patients with $\cup C$ were in remission at the time of the switch and $65.3 \%(18 / 28)$ were in remission at 12 months. No significant changes in the median partial Mayo score $(P=0.058)$ or $C R P(P=0.329)$ were observed at 12 months. Serious adverse events related to medication were reported in 11 (11.2\%) patients.

Conclusion Switching from infliximab RP to CT-P13 is efficacious and well tolerated in patients with CD or UC for up to 12 months. Eur J Gastroenterol Hepatol 29:1290-1295

Copyright (C) 2017 The Author(s). Published by Wolters Kluwer Health, Inc.

\section{Introduction}

Over the past 20 years, the introduction of biological agents into clinical practice has radically improved outcomes in patients with immune-mediated inflammatory diseases. This includes the two major types of inflammatory bowel disease (IBD): Crohn's disease (CD) and ulcerative colitis (UC) [1]. Tumor necrosis factor- $\alpha$ (TNF$\alpha)$ antagonists, such as infliximab, act by preventing TNF$\alpha$ from binding to its receptor, neutralizing its activity and

\footnotetext{
European Journal of Gastroenterology \& Hepatology 2017, 29:1290-1295

Keywords: biosimilar agent, Crohn's disease, CT-P13, inflammatory bowel disease, infliximab, ulcerative colitis

aDepartment of Gastroenterology, University Virgen Macarena Hospital, bDepartment of Preventive Medicine and Public Health, Virgen Macarena University Hospital, 'Department of Pharmacology, Virgen Macarena University Hospital and dDepartment of Gastroenterology, Virgen del Rocío University Hospital, Institute of Biomedicie of Seville (IBIS), University of Seville, Seville, Spain Correspondence to Federico Argüelles-Arias, MD, PhD, University Hospital Virgen Macarena, Seville, Spain

Tel: + 349550088 01; fax: + 349550088 05; e-mail: farguelles@telefonica.net Received 18 April 2017 Accepted 23 June 2017

This is an open-access article distributed under the terms of the Creative Commons Attribution-Non Commercial-No Derivatives License 4.0 (CCBY-NC-ND), where it is permissible to download and share the work provided it is properly cited. The work cannot be changed in any way or used commercially without permission from the journal.
}

alleviating mucosal inflammation [2]. In Europe, the antiTNF- $\alpha$ agents authorized by the European Medicines Agency (EMA) for use in IBD are infliximab [3], adalimumab [4], and golimumab [5]. However, biological agents are much more expensive than traditional treatments, and the high cost of these drugs in the treatment of IBD imposes a considerable burden on the national healthcare system [6]. As a result, interest in biosimilars has grown as biosimilar agents are highly similar in terms of quality, efficacy, and safety to already licensed biologics [7] but are associated with lower development costs. Thus, biosimilars may be available at a lower price and have the potential to offer considerable cost savings to healthcare systems [8].

CT-P13 (Remsima and Inflectra) is a biosimilar of infliximab (Remicade), which is its reference product (RP). Both CT-P13 and infliximab RP are chimeric immunoglobulin G1 monoclonal antibodies produced in cell lines derived from the same cell type of murine hybridoma. These monoclonal antibodies have an identical amino acid sequence and highly comparable higher-order structures [9].

CT-P13 was authorized by the EMA in 2013 for several indications, including IBD [10], based on two pivotal clinical trials in patients with rheumatoid arthritis (RA) and ankylosing spondylitis. The efficacy and pharmacokinetic equivalence of CT-P13 and infliximab RP were demonstrated in these two randomized trials at 30 weeks, and safety profiles were comparable for both infliximab 
formulations $[11,12]$. Results up to week 54 demonstrated continued comparability between CT-P13 and its RP in both patient populations $[13,14]$. Furthermore, in extensions of these studies, similar efficacy and safety profiles were observed in patients with RA and ankylosing spondylitis who switched from RP to CT-P13 for an additional year compared with those who continued CT-P13 treatment for 2 years $[15,16]$. In patients with IBD, a number of observational studies of CT-P13 in clinical practice in both anti-TNF- $\alpha$-naive patients [17-22] and those who have been switched from infliximab RP $[23,24]$ have been published with good results. Furthermore, results from the randomized, phase IV, double-blind, parallel-group NORSWITCH study (NCT02148640) have recently been reported [25] and other similar randomized controlled trials have been initiated in patients with IBD $[26,27]$ but are either ongoing or awaiting results. On the basis of the current regulatory guidance from the EMA, and the evidence for efficacy and safety of biosimilars in patients with IBD, the European Crohn's Colitis Organisation has recently published its position statement on the use of biosimilars for IBD [28] and states that 'when a biosimilar product is registered in the European Union, it is considered to be as efficacious as the reference product when used in accordance with the information provided in the Summary of Product Characteristics'. The consensus statement supports switching between an originator and biosimilar product, but notes the lack of data regarding reverse switching, multiple switching, and cross-switching among biosimilars in IBD patients, and further explains that demonstration of the safety of biosimilars requires large observational studies with long-term follow-up in this patient group.

Until data from randomized controlled trials in CD and UC are available, results from 'real-world' clinical use of the biosimilar can offer valuable insights into its efficacy and safety. Here, we describe an observational study assessing the efficacy and safety of switching from infliximab RP to CT-P13 in patients with IBD for up to 12 months.

\section{Materials and methods}

\section{Study design}

This was a prospective observational study conducted at the Virgen Macarena Hospital (Seville, Spain) from March 2015 to February 2016. The study was approved by the Research Ethics Committee of the Virgen Macarena Hospital. Good clinical practice guidelines were followed and written informed consent was obtained from all patients.

\section{Patients}

Patients with moderate to severe CD or UC who had previously been treated with and had responded to infliximab RP were included in the study. Montreal classification status was recorded in all patients before enrollment. All patients were switched from infliximab RP (Remicade; Janssen Biologics B.V., Leiden, The Netherlands) to CTP13 (Remsima; Celltrion, Incheon, South Korea) and treated according to the dosage and regime recommended by the Summary of Product Characteristics of Remsima in Spain [29]. All patients received intravenous corticosteroids and antihistamines as premedication before the infusion treatment.

\section{Study endpoints and assessments}

The efficacy endpoint was the change in clinical remission in patients switched from infliximab RP assessed at 12 months, according to the Harvey-Bradshaw (HB) score for patients with $\mathrm{CD}$ and the partial Mayo score for patients with UC.

The HB and partial Mayo scores were assessed by the treating physician in consultations held every 3 months. Changes in C-reactive protein (CRP), and in the $\mathrm{HB}$ and partial Mayo scores, were reported in all patients in remission at 12 months.

In patients with $\mathrm{CD}$ and $\mathrm{UC}$ who were in remission at the time of the switch, remission was considered to be maintained if the patient remained in clinical remission (HB score $\leq 4$ in patients with CD or partial Mayo score $\leq 2$ in patients with UC) after switching without the need for steroids, surgery, or increased dosage. In patients with CD and UC who were not in remission at the time of the switch, remission was considered to be achieved when a $\mathrm{HB}$ score less than or equal to 4 (in patients with $\mathrm{CD}$ ) or a partial Mayo score less than or equal to 2 (in patients with UC) was reached. The HB and partial Mayo scores in patients with $\mathrm{CD}$ and UC, respectively, and CRP in all patients were compared from month 0 to month 12 .

Adverse events (AE) were monitored from the first infusion of CT-P13 until the end of the study and were recorded according to the Office of Human Research Protection [30].

\section{Statistical analysis}

Demographic and nominal results were reported in percentages and frequencies. Numerical results were reported as average and SD in cases of normal distribution and as median and interquartile range (IQR) in cases of skewed distribution. The Cochrane's $Q$ test and the Friedman test were used to analyze the evolution of the clinical scores (HB score and partial Mayo score) and CRP values of patients. The $95 \%$ confidence intervals $(95 \%$ CIs) were calculated and $\alpha$ was set at 0.05 for the determination of statistical significance. Analyses were performed using SPSS 23 (IBM Corporation, Armonk, New York, USA).

\section{Results}

\section{Patients}

A total of 98 patients with IBD (67 with CD and 31 with UC) were included in this study. The median (range) age of patients with CD was $42(38-44)$ years and for patients with UC was $43(38-48)$ years. Over half of the patient population $(56.1 \% ; n=55)$ were men and $68.3 \%(n=67)$ were nonsmokers. In all, $56.7 \%$ with CD and $38.7 \%$ with UC used concomitant thiopurines. The baseline demographics and phenotypic characteristics of patients with $\mathrm{CD}$ and UC according to the Montreal classification and prior medication exposure are shown in Table 1.

In the $\mathrm{CD}$ patient group, median (IQR) duration of ongoing infliximab RP treatment at the start of the study was $297(158-432)$ weeks. Patient withdrawals from this 


\begin{tabular}{|c|c|c|}
\hline Characteristics & $n=98[n(\%)]$ & $95 \% \mathrm{Cl}$ \\
\hline \multicolumn{3}{|l|}{ Sex } \\
\hline Men & $55 / 98(56.1)$ & $45.8-66.5$ \\
\hline Women & 43/98 (43.9) & $33.5-54.2$ \\
\hline \multicolumn{3}{|l|}{ Age, median (range), years } \\
\hline Crohn's disease & $42(38-44)$ & \\
\hline Ulcerative colitis & $43(38-48)$ & \\
\hline \multicolumn{3}{|l|}{ Smoking status } \\
\hline Never & 67/98 (68.3) & $58.7-78.1$ \\
\hline Previous & 18/98 (18.4) & $10.2-26.5$ \\
\hline Current & 13/98 (13.3) & $6.0-20.5$ \\
\hline \multicolumn{3}{|l|}{ CD patients } \\
\hline \multicolumn{3}{|l|}{ Age at diagnosis } \\
\hline$A 1$ (<16 years) & 7/ 67 (10.4) & $2.4-18.5$ \\
\hline A2 ( $16-40$ years) & 49/67 (73.1) & $61.8-84.5$ \\
\hline АЗ (>41 years) & $11 / 67(16.4)$ & $6.8-26.0$ \\
\hline \multicolumn{3}{|l|}{ Location at diagnosis } \\
\hline L1 (ileal) & 18/67 (26.9) & $15.5-38.2$ \\
\hline L2 (colonic) & 26/67 (38.8) & $26.4-51.2$ \\
\hline L3 (ileocolonic) & 21/67 (31.3) & $19.5-43.2$ \\
\hline L4 (upper gastrointestinal tract) & 2/67 (3) & $0.3-10.4$ \\
\hline \multicolumn{3}{|l|}{ Disease behavior } \\
\hline B1 (nonstricturing, nonpenetrating) & 38/67 (56.7) & $44.1-69.3$ \\
\hline B2 (stricturing) & $14 / 67$ (20.9) & $10.4-31.4$ \\
\hline B3 (penetrating) & $15 / 67(22.4)$ & $11.7-33.1$ \\
\hline \multicolumn{3}{|l|}{ Perianal disease } \\
\hline Proportion of patients with perianal disease & $37 / 67(55.2)$ & $42.6-67.9$ \\
\hline \multicolumn{3}{|l|}{ Extraintestinal manifestations } \\
\hline $\begin{array}{l}\text { Proportion of patients with no extraintestinal } \\
\text { manifestations }\end{array}$ & $42 / 67(62.7)$ & $50.4-75.0$ \\
\hline \multicolumn{3}{|l|}{ UC patients } \\
\hline \multicolumn{3}{|l|}{ Extent (UC) } \\
\hline E1 (proctitis) & 13/31 (41.9) & $22.9-60.9$ \\
\hline E2 (left sided colitis) & 10/31 (32.3) & $14.2-50.3$ \\
\hline E3 (pancolitis) & $8 / 31(25.8)$ & $8.8-42.9$ \\
\hline \multicolumn{3}{|l|}{ Severity } \\
\hline S1 (mild) & $11 / 31(35.5)$ & $17-53.9$ \\
\hline S2 (moderate) & $16 / 31(51.6)$ & $32.4-70.8$ \\
\hline S3 (severe) & 4/31 (12.9) & $3.6-29.8$ \\
\hline \multicolumn{3}{|l|}{ Extraintestinal manifestations } \\
\hline $\begin{array}{l}\text { Proportion of patients with no extraintestinal } \\
\text { manifestations }\end{array}$ & 26/31 (83.9) & $66.3-94.5$ \\
\hline \multicolumn{3}{|l|}{ Prior medication exposure } \\
\hline \multicolumn{3}{|l|}{ Thiopurines } \\
\hline CD & 48/67 (71.6) & $60.1-83.2$ \\
\hline UC & 27/31 (87.1) & $70.2-96.4$ \\
\hline \multicolumn{3}{|l|}{ Methotrexate } \\
\hline $\mathrm{CD}$ & 20/67 (29.9) & $18.1-41.5$ \\
\hline UC & $5 / 31(16.1)$ & $5.4-33.7$ \\
\hline \multicolumn{3}{|l|}{ Concomitant medications use } \\
\hline \multicolumn{3}{|l|}{ 5-aminosalicylic acid } \\
\hline CD & 20/67 (29.9) & $18.1-41.5$ \\
\hline UC & 22/31 (70.9) & $53.4-88.6$ \\
\hline \multicolumn{3}{|l|}{ Thiopurines } \\
\hline CD & $38 / 67(56.7)$ & $44.1-69.3$ \\
\hline UC & 12/31 (38.7) & $19.9-57.5$ \\
\hline Methotrexate & & \\
\hline $\mathrm{CD}$ & 10/67 (14.9) & $5.6-24.2$ \\
\hline UC & $3 / 31(9.7)$ & $2.0-25.7$ \\
\hline
\end{tabular}

$\mathrm{CD}$, Crohn's disease; $\mathrm{Cl}$, confidence interval; UC, ulcerative colitis.

group were as follows: at 3 months post switch, one patient was withdrawn because of an AE; at 6 months, two had discontinued treatment (one patient because of an AE; one patient required surgery); at 9 months, one patient was withdrawn because of an AE; and at 12 months, a further two patients did not continue treatment (one patient because of an $\mathrm{AE}$, and one patient did not attend follow-up visits).

In the UC patient group, median (IQR) duration of ongoing infliximab RP treatment at the start of the study was 203 (42-294) weeks. At 6 months post switch, three patients stopped treatment: two because of clinical and endoscopic remission and one because of a lack of response to treatment. At 12 months post switch, another three patients discontinued treatment: one because of a lack of response to treatment, one because of maintained remission with mucosa healing, and one because of an AE.

\section{Efficacy}

\section{Crohn's disease patient group}

At the start of this study, 83.6\% (56/67) of patients with $\mathrm{CD}$ were in remission. After patients were switched from infliximab RP to CT-P13, 79.1\% (53/67), 76.1\% (51/67), $71.6 \%(48 / 67)$, and $62.7 \%(42 / 67)$ of CD patients were in remission at 3, 6, 9, and 12 months, respectively (Fig. 1). In total, $91.0 \%(61 / 67)$ of patients with $\mathrm{CD}$ completed 12 months of follow-up.

In total, 56 patients were in remission at the time of switch. Of the patients in remission at months 3, 6, 9 and 12, respectively, $87.5 \%$ (49/56), $83.9 \%$ (47/56), $76.4 \%$ $(42 / 55)$, and $69.8 \%(37 / 53)$ had remained in remission since switching, with statistically significant differences observed over this period $(P=0.034)$. Of the 11 patients who were not in remission at the time of switch, 4, 5, 4, and 5 patients reached remission at 3,6,9, and 12 months, respectively, post switch.

The HB score showed significant changes over the 12-month period [median HB score (95\% CI): 1 (1-2); 1 (1-3); $1(1-3) ; 2$ (1-2); 1 (1-3) at months $0,3,6,9$, and 12, respectively; $P<0.001]$. The difference was observed between months 0 and $9(P=0.010)$, and months 0 and 12 $(P=0.007)$. No significant changes in median $(95 \% \mathrm{CI}) \mathrm{CRP}$ levels were observed in patients with $\mathrm{CD}$ over the same period [1 (0-6); $1(0-6.3) ; 2(0-6.5) ; 1(0.1-3.7) ; 0.36(0.2-2)$ at 0,3 , 6,9 , and 12 months, respectively; $P=0.364$ ] (Fig. 2).

\section{Ulcerative colitis patient group}

At the start of the study, $80.6 \%$ (25/31) of patients with UC were in remission. After patients were switched from infliximab RP to CT-P13, 77.4\% (24/31), 75.9\% (22/29), $69.0 \%(20 / 29)$, and $64.3 \%(18 / 28)$ of patients were in remission at 3, 6, 9, and 12 months, respectively (Fig. 3). In total, $80.6 \%(25 / 31)$ of patients with UC completed 12 months of follow-up.

Overall, 25 patients with UC were in remission at the time of the switch. Of the patients in remission at 3, 6, 9, and 12 months, respectively, 92.0\% (23/25), 91.3\% (21/23), $82.6 \%(19 / 23)$, and $81.0 \%$ (17/21) had maintained remission since switching, without statistically significant differences $(P=0.700)$. Of the six patients with UC who were not

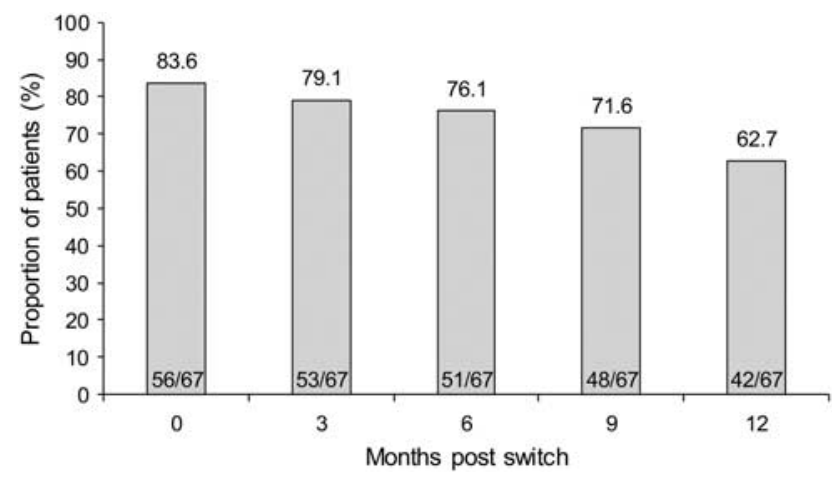

Fig. 1. Global remission in patients with Crohn's disease. 


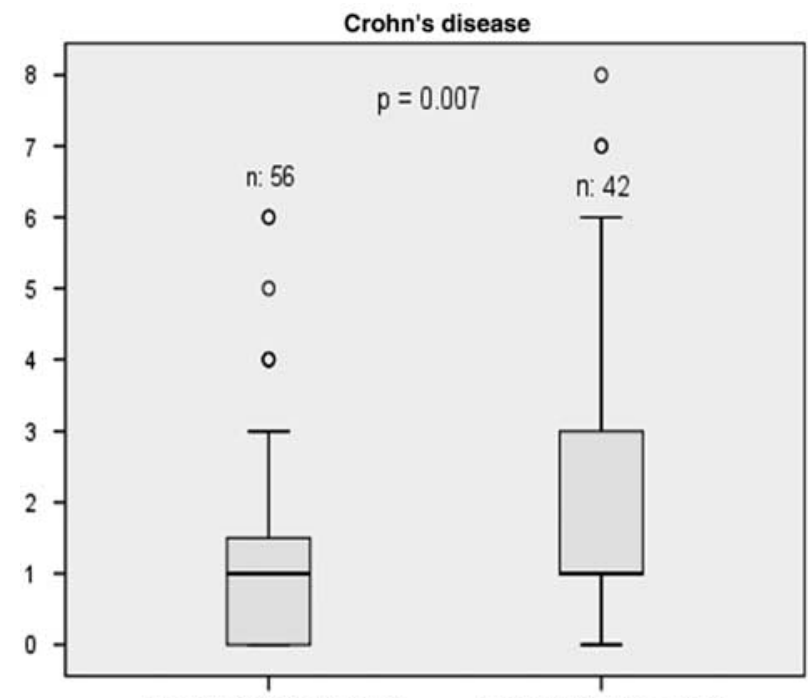

Harvey-Bradshaw basal

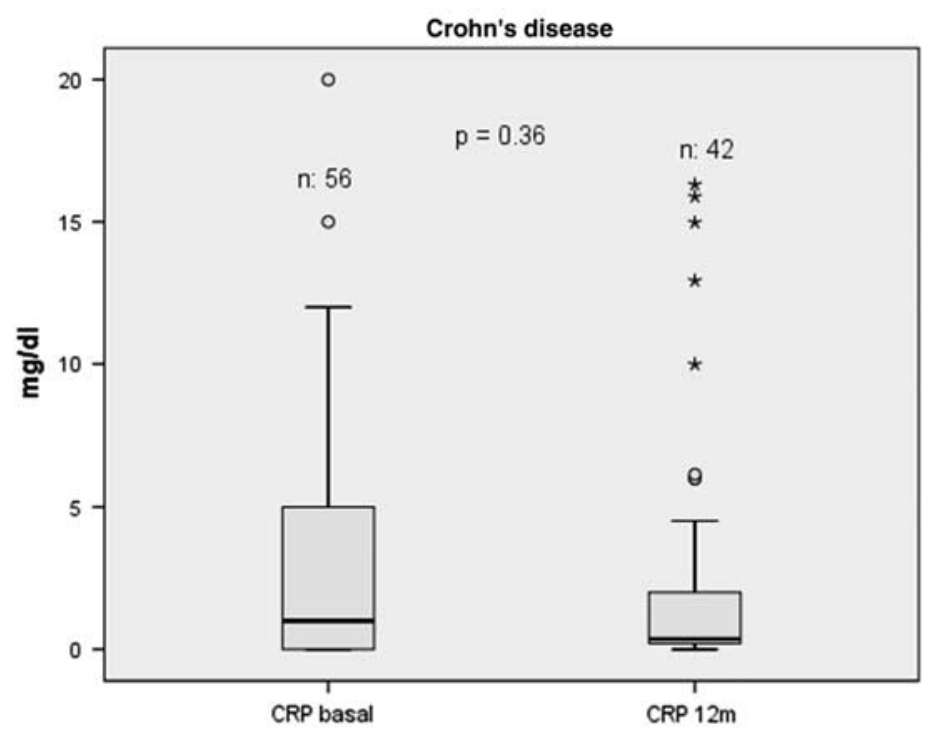

Fig. 2. Evolution of Harvey-Bradshaw score and C-reactive protein from 0 to 12 months. CRP, C-reactive protein.

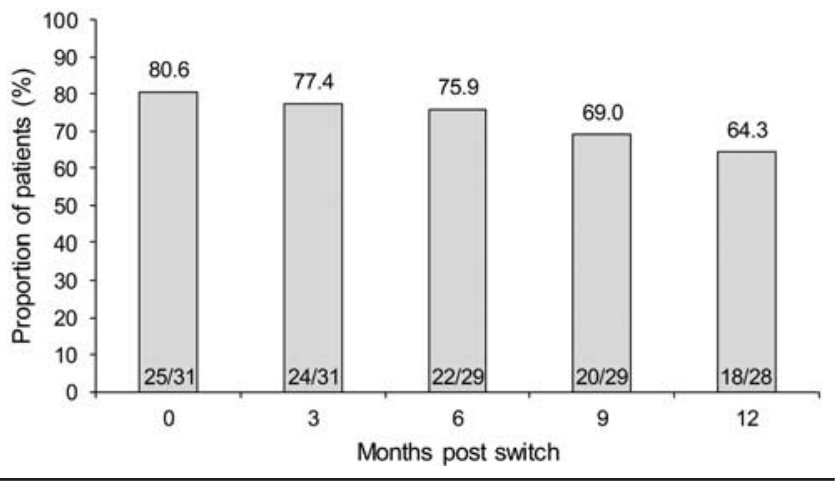

Fig. 3. Global remission in patients with ulcerative colitis.

in remission at the time of the switch, only one patient reached remission at 3,6, 9, and 12 months.

No significant changes in the median $(95 \%$ CI) partial Mayo score were observed in switched patients over the 12 months [2 (1-3); $1(1-3) ; 1(0-9) ; 1(0-4) ; 1(0-3)$ at 0 , $3,6,9$, and 12 months, respectively; $P=0.058$ ]. No significant changes in the median CRP level $(95 \% \mathrm{CI})$ were observed over the same period [2 (1-10); $1(0-2) ; 1(0-5)$; $1(0-2) ; 0.5(0.2-1.4)$ at months $0,3,6,9$, and 12, respectively; $P=0.329$ ] (Fig. 4).

\section{Safety}

In total, 11 AEs occurred in 11/98 (11.2\%) patients: one skin reaction, one case of abdominal pain, two cases of headache and two of paresthesia during infusion, one case of Sweet's syndrome, two of polyarthralgia, and two of palpitations. Six patients discontinued treatment because of AEs. Two AEs were considered to be serious: one patient with CD who had Sweet's syndrome needed hospitalization and discontinued treatment. In addition, one patient with UC discontinued because of paresthesia during the infusion.

\section{Discussion}

Until data from randomized controlled trials of CT-P13 in CD and UC are available, results from its use in clinical practice can provide valuable information relating to the efficacy and tolerability of the biosimilar in these indications. Here we report results from the first prospective observational study that analyzes the response of switching to CT-P13 from infliximab RP in patients with IBD at 12 months. Results indicate that CT-P13 treatment is effective and safe for up to 1 year in patients switched from infliximab RP. At 12 months, remission was maintained in $69.8 \%(37 / 53)$ of patients with CD and $81.0 \%$ (17/21) of patients with UC. Thus, disease worsening occurred in 30.2 and $19.0 \%$ of patients with CD and UC who were in remission at study commencement, respectively. Among $\mathrm{CD}$ patients, $\mathrm{HB}$ score was significantly altered between baseline and months 9 and 12, yet despite these changes the median overall score did not fall outside the classification of remission $(<5)$. No significant changes in median partial Mayo score were observed in UC patients and CRP levels remained unchanged in both groups.

As is well known, monoclonal antibodies that target TNF- $\alpha$ are effective for the induction and maintenance of remission in IBD [31]. However, many patients who initially respond to these treatments later experience a loss of efficacy, coinciding with a flare of symptoms. A review by Gisbert and Panes [32] found that 37\% of patients with CD lost their response to infliximab and calculated the annual risk for this loss to be $13 \%$ per patient per year [32]. In the ACT I and II trials, $~ 45 \%$ of patients with UC had a sustained response to infliximab at week 54, meaning that $55 \%$ of patients lost their response during the year $[33,34]$. Similarly, in a retrospective study, 59\% of patients with UC demonstrated a secondary loss of response during maintenance treatment with infliximab, at a mean time of 59 weeks [35]. The results of the current study support these previous findings.

In our study, patients were switched from infliximab RP to CT-P13 and the clinical response monitored for 12 months. Unfortunately, few similar studies exist with 

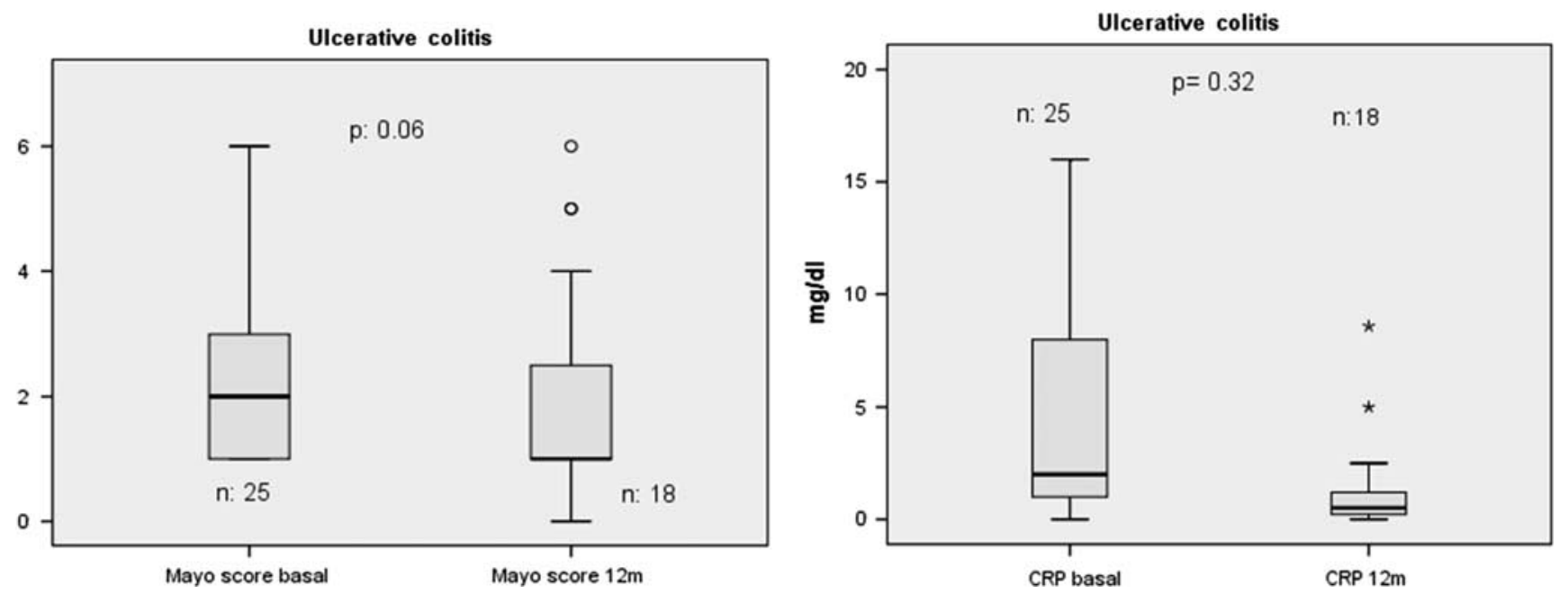

Fig. 4. Evolution of partial Mayo score and C-reactive protein from 0 to 12 months. CRP, C-reactive protein.

which to compare our results. The NOR-SWITCH trial did include patients with IBD who were switched from infliximab RP to CT-P13 [27], in addition to patients with RA, spondyloarthritis, psoriatic arthritis, and chronic plaque psoriasis. For all indications, disease worsening occurred in $26.2 \%$ in the infliximab RP arm and $29.6 \%$ in the CT-P13 arm. The worsening rate in patients with CD was $36.5 \%$ and in patients with UC it was $11.9 \%$. Our results could be considered better in the case of CD $(30.2 \%)$ and worse for UC $(19.0 \%)$. However, the NORSWITCH trial was not powered to assess changes within each indication, so these results must be interpreted with caution. In addition, in our study we considered that a patient was in remission at switching if he were on stable infliximab RP treatment at that time, applying generic and disease-specific outcome measures, whereas in the NORSWITCH study the patient must have been on stable infliximab RP treatment for at least 6 months to be eligible for participation. In the PROSIT-BIO study, 97 patients with CD switched to CT-P13 after a mean of $18 \pm 14$ infusions of infliximab RP. After 8, 16, and 24 weeks 94.5, 90.8 , and $78.9 \%$ maintained efficacy of treatment [36].

All observational postmarketing studies published to date have reported positive outcomes for efficacy measures in patients with CD and UC treated with CT-P13, irrespective of prior anti-TNF- $\alpha$ treatment [17-24]. Jung et al. [17] studied a total of 110 patients with IBD treated with CT-P13, which included 36 patients who were switched from infliximab RP. In these patients, 92.6\% (25/27) of patients with CD and $66.7 \%$ (6/9) of patients with UC maintained a similar efficacy compared with previous infliximab treatment. Smits et al. [23] studied a cohort of 83 Remicade-treated patients with IBD who were switched to CT-P13. They found that disease activity remained stable after switching and that over $80 \%$ of patients maintained clinical remission.

In the current study, AEs occurred in 11 of the 98 $(11.2 \%)$ patients with IBD. To date, no unexpected treatment-emergent adverse events (TEAEs) have been observed in patients with CD and UC treated with CT-P13 [17-25]. A Korean study in 95 patients with CD and 78 patients with UC treated with CT-P13 reported that treatment-related TEAEs occurred in $10 \%$ of patients.
Most of these were mild to moderate in severity; however, five serious TEAEs were also reported [19].

Our study has some limitations. First of all, and perhaps most importantly, as an observational study of the longterm efficacy and safety of switching from infliximab RP to CT-P13 in patients with IBD, our study demonstrates the long-term outcomes of these patients, but does not enable us to comment on the comparative efficacy compared with patients who did not switch. Similarly, we could not measure drug trough levels or the presence of antidrug antibodies as has been done in other studies. Therefore, it has not been possible to ascertain the cause of the loss of response observed in some patients. We were also unable to measure mucosal healing or fecal calprotectin as a biomarker of relapse in patients with IBD.

In conclusion, this study provides valuable data on the long-term efficacy of CT-P13 maintenance treatment after switching from infliximab RP, and demonstrates effectiveness and safety at 12 months.

\section{Acknowledgements}

The authors would like to thank Dr Ana Moreno Cerro on behalf of Springer Healthcare Communications, who provided medical writing assistance. Medical writing support was funded by Kern Pharma. Further editing support was provided by Alice Wareham PhD (Aspire Scientific Ltd, Bollington, UK) and funded by Celltrion Healthcare Co, Ltd.

\section{Conflicts of interest}

F Argüelles-Arias has participated in advisory boards and has received financial support to attend scientific meetings from Kern Pharma. M.F. Guerra Veloz, R. Perea Amarillo, L. Castro Laria, B. Maldonado Pérez, D. Chaaro Benallal, and A. Benítez Roldán have received financial support to attend scientific meetings from Kern Pharma. A. VilchesArenas, V. Merino, G. Ramírez, M.A. Calleja-Hernández, A. Caunedo Álvarez, and M. Romero Gómez have no conflicts of interest. 


\section{References}

1 Cote-Daigneault J, Bouin M, Lahaie R, Colombel JF, Poitras P. Biologics in inflammatory bowel disease: what are the data? United European Gastroenterol J 2015; 3:419-428.

2 Tracey D, Klareskog L, Sasso EH, Salfeld JG, Tak PP. Tumor necrosis factor antagonist mechanisms of action: a comprehensive review. Pharmacol Ther 2008; 117:244-279.

3 European Medicines Agency. European public assessment reports Infliximab. Available at: http://www.ema.europa.eu/ema/index.jsp?curl= pages/medicines/landing/epar_search.jsp\&mid=WC0b01ac058001d124 \&source=homeMedSearch\&keyword=infliximab\&category=human\&isNew Query=true. [Accessed 23 January 2017].

4 European Medicines Agency. European public assessment reports Adalimumab. Available at: http://www.ema.europa.eu/ema/index.jsp? curl=pages/medicines/landing/epar_search.jsp\&mid=\%0AWCOb01 ac058001 1124\&source=homeMedSearch\&keyword=adalimumab\&ca tegory=human\&isNewQuery=true. [Accessed 23 January 2017].

5 European Medicines Agency. European public assessment reports Simponi (golimumab). Available at: $h$ ttp://www.ema.europa.eu/ema/index. jsp?curl=pages/medicines/human/medicines/000992/human_med_ 001053.jsp\&mid=WCOb01ac058001d124. [Accessed 23 January 2017].

6 Bodger K, Kikuchi T, Hughes D. Cost-effectiveness of biological therapy for Crohn's disease: Markov cohort analyses incorporating United Kingdom patient-level cost data. Aliment Pharmacol Ther 2009; 30:265-274.

7 World Health Organization. Expert Committee on biological standarization. Guidelines on evaluation of similar biotherapeutic products (SBPs). Geneva, 19-23 October 2009. Available at: $h$ ttp://www.who.int/ biologicals/areas/biological_therapeutics/BIOTHERAPEUTICS_FOR_ WEB_22APRIL2010.pdf. [Accessed 23 January 2017].

8 Haustein R, de Millas C, Höer A, Häyssker B. Saving money in the European healthcare systems with biosimilars. GaBI J 2012; $1: 120-126$.

9 European Medicines Agency. Committee for medicinal products for human use (CHMP). Assessment report: Remsima (infliximab); 2013. Available at: http://www.ema.europa.eu/docs/en_GB/document_ library/EPAR_-_Public_assessment_report/human/002576/WC500151 486.pdf. [Accessed 23 January 2017].

10 European Medicines Agency. EPAR summary for the public. Remsima; 2013. Available at: http://www.ema.europa.eu/docs/en_GB/docu ment_library/EPAR_-_Summary_for_the_public/human/002576/ WC500150872.pdf. [Accessed 23 January 2017].

11 Yoo DH, Hrycaj P, Miranda P, Ramiterre E, Piotrowski M, Shevchuk S, et al. A randomised, double-blind, parallel-group study to demonstrate equivalence in efficacy and safety of CT-P13 compared with innovator infliximab when coadministered with methotrexate in patients with active rheumatoid arthritis: the PLANETRA study. Ann Rheum Dis 2013; 72:1613-1620.

12 Park W, Hrycaj P, Jeka S, Kovalenko V, Lysenko G, Miranda P, et al. A randomised, double-blind, multicentre, parallel-group, prospective study comparing the pharmacokinetics, safety, and efficacy of CT-P13 and innovator infliximab in patients with ankylosing spondylitis: the PLANETAS study. Ann Rheum Dis 2013; 72:1605-1612.

13 Yoo DH, Racewicz A, Brzezicki J, Yatsyshyn R, Arteaga ET, Baranauskaite $\mathrm{A}$, et al. A phase III randomized study to evaluate the efficacy and safety of CT-P13 compared with reference infliximab in patients with active rheumatoid arthritis: 54-week results from the PLANETRA study. Arthritis Res Ther 2016; 18:82.

14 Park W, Yoo DH, Jaworski J, Brzezicki J, Gnylorybov A, Kadinov V, et al. Comparable long-term efficacy, as assessed by patient-reported outcomes, safety and pharmacokinetics, of CT-P13 and reference infliximab in patients with ankylosing spondylitis: 54-week results from the randomized, parallel-group PLANETAS study. Arthritis Res Ther 2016; 18:25.

15 Yoo DH, Prodanovic N, Jaworski J, Miranda P, Ramiterre E, Lanzon A, et al. Efficacy and safety of CT-P13 (biosimilar infliximab) in patients with rheumatoid arthritis: comparison between switching from reference infliximab to CT-P13 and continuing CT-P13 in the PLANETRA extension study. Ann Rheum Dis 2017; 76:355-363.

16 Park W, Yoo DH, Miranda P, Brzosko M, Wiland P, Gutierrez-Urena S, et al. Efficacy and safety of switching from reference infliximab to CTP13 compared with maintenance of CT-P13 in ankylosing spondylitis: 102-week data from the PLANETAS extension study. Ann Rheum Dis 2017; 76:346-354.

17 Jung YS, Park DI, Kim YH, Lee JH, Seo PJ, Cheon JH, et al. Efficacy and safety of CT-P13, a biosimilar of infliximab, in patients with inflammatory bowel disease: a retrospective multicenter study. J Gastroenterol Hepatol 2015; 30:1705-1712.

18 Argüelles-Arias F, Guerra Veloz MF, Perea Amarillo R, Vilches-Arenas A, Castro Laria L, Maldonado Pérez B, et al. Effectiveness and safety of CT-P13 (Biosimilar Infliximab) in patients with inflammatory bowel disease in real life at 6 months. Dig Dis Sci 2017; 62:1305-1312.

19 Gecse KB, Lovasz BD, Farkas K, Banai J, Bene L, Gasztonyi B, et al. Efficacy and safety of the biosimilar infliximab CT-P13 treatment in inflammatory bowel diseases: a prospective, multicentre, nationwide cohort. J Crohns Colitis 2016; 10:133-140.

20 Park SH, Kim YH, Lee JH, Kwon HJ, Lee SH, Park DI, et al. Post-marketing study of biosimilar infliximab (CT-P13) to evaluate its safety and efficacy in Korea. Expert Rev Gastroenterol Hepatol 2015; 9 (Suppl 1): 35-44.

21 Farkas K, Rutka M, Golovics PA, Vegh Z, Lovasz BD, Nyari T, et al. Efficacy of infliximab biosimilar CT-P13 induction therapy on mucosal healing in ulcerative colitis. J Crohns Colitis 2016; 10:1273-1278.

22 Jahnsen J. Clinical experience with infliximab biosimilar Remsima (CTP13) in inflammatory bowel disease patients. Therap Adv Gastroenterol 2016; 9:322-329.

23 Smits LJ, Derikx LA, de Jong DJ, Boshuizen RS, van Esch AA, Drenth JP, Hoentjen F. Clinical outcomes following a switch from Remicade $(\mathrm{R})$ to the biosimilar CT-P13 in inflammatory bowel disease patients: a prospective observational cohort study. J Crohns Colitis 2016; 10:1287-1293.

24 Sieczkowska J, Jarzebicka D, Banaszkiewicz A, Plocek A, Gawronska A, Toporowska-Kowalska E, et al. Switching between infliximab originator and biosimilar in paediatric patients with inflammatory bowel disease. Preliminary observations. J Crohns Colitis 2016; 10:127-132.

25 Goll GL, Olsen IC, Jorgensen KK, Lorentzen M, Bolstad N, Haavardsholm EA, , et al Biosimilar Infliximab (CT-P13) is not inferior to originator infliximab: results from a 52-week randomized switch trial in Norway. 2016 ACR/ARHP Annual Meeting. Abstract 19L. Available at: http://acrabstracts.org/abstract/biosimilar-infliximab-ct-p13-is-not-infer ior-to-originator-infliximab-results-from-a-52-week-randomized-switchtrial-in-norway/. [Accessed 23 January 2017].

26 ClinicalTrials.gov. Demonstrate noninferiority in efficacy and to assess safety of CT-P13 in patients with active Crohn's disease. Available at: $h$ ttps:// clinicaltrials.gov/ct2/show/NCT02096861. [Accessed 23 January 2017].

27 ClinicalTrials.gov. To evaluate the safety and efficacy of Remsima in patients with Crohn's disease (CD) or ulcerative colitis (UC). Available at: https:// clinicaltrials.gov/ct2/show/NCT02326155. [Accessed 23 January 2017].

28 Danese S, Fiorino G, Raine T, Ferrante M, Kemp K, Kierkus J, et al. ECCO position statement on the use of biosimilars for inflammatory bowel disease-an update. J Crohns Colitis 2017; 11:26-34.

29 European Medicines Agency. Ficha técnica de Remsima, INN - infliximab. Available at: $h t t p: / / w w w . e m a . e u r o p a . e u / d o c s / e s \_E S / d o c u m e n t$ library/EPAR_-_Product_Information/human/002576/WC500150871. pdf. [Accessed 23 January 2017].

30 US Department of Health and Human Services - Office for Human Research Protections. . Unanticipated problems involving risks \& adverse events guidance (2007). Available at: http://www.hhs.gov/ohrp/ regulations-and-policy/guidance/reviewing-unanticipated-problems/ index.html. [Accessed 23 January 2017].

31 Hanauer SB, Feagan BG, Lichtenstein GR, Mayer LF, Schreiber S, Colombel JF, et al. Maintenance infliximab for Crohn's disease: the ACCENT I randomised trial. Lancet 2002; 359:1541-1549.

32 Gisbert JP, Panes J. Loss of response and requirement of infliximab dose intensification in Crohn's disease: a review. $\mathrm{Am} J$ Gastroenterol 2009; 104:760-767.

33 Rutgeerts P, Sandborn WJ, Feagan BG, Reinisch W, Olson A, Johanns $\mathrm{J}$, et al. Infliximab for induction and maintenance therapy for ulcerative colitis. N Engl J Med 2005; 353:2462-2476.

34 Reinisch W, Sandborn WJ, Rutgeerts P, Feagan BG, Rachmilewitz D, Hanauer SB, et al. Long-term infliximab maintenance therapy for ulcerative colitis: the ACT-1 and -2 extension studies. Inflamm Bowel Dis 2012; 18:201-211.

35 Ma C, Huang V, Fedorak DK, Kroeker KI, Dieleman LA, Halloran BP, Fedorak RN. Outpatient ulcerative colitis primary anti-TNF responders receiving adalimumab or infliximab maintenance therapy have similar rates of secondary loss of response. J Clin Gastroenterol 2015; 49:675-682.

36 Fiorino G, Manetti N, Armuzzi A, Orlando A, Variola A, Bonovas S, et al. The PROSIT-BIO cohort: a prospective observational study of patients with inflammatory bowel disease treated with infliximab biosimilar. Inflamm Bowel Dis 2017; 23:233-243. 